\title{
Reação de genótipos de Stylosanthes capitata à antracnose
}

\author{
Josani da Silva Falco ${ }^{1,2}$, Celso Dornelas Fernandes ${ }^{2}$, Jaqueline Rosemeire Verzignassi ${ }^{2}$, Guilherme Mallmann ${ }^{2}$, \\ Carolina de Arruda Queiróz ${ }^{2}$, Haroldo Antunes Chagas ${ }^{2}$, Margareth Vieira Batista ${ }^{2}$ e Francisco Antônio Quetez ${ }^{2}$.
}

${ }^{1}$ Trabalho extraído da dissertação de mestrado da primeira autora. Bolsista CAPES. ${ }^{2}$ Embrapa Gado de Corte, Av. Rádio Maia, 830, Zona Rural, CEP 79106-550, Campo Grande, Mato Grosso do Sul, Brasil.

Autor para correspondência: Jaqueline Verzignassi (jaqueline.verzignassi@embrapa.br).

Data de chegada: 14/11/2014. Aceito para publicação em: 26/08/2015.

$10.1590 / 0100-5405 / 2055$

\section{RESUMO}

Falco, J.S.; Fernandes, C.D.; Verzignassi, J.R.; Mallmann, G.; Queiróz, C.A.; Chagas, H.A.; Batista, M.V.; Quetez, F.A. Reação de genótipos de Stylosanthes capitata à antracnose. Summa Phytopathologica, v.42, n.2, p.140-148, 2016.

O Brasil detém o maior rebanho bovino comercial do mundo, baseado na utilização de pastagens. Atualmente, o uso de leguminosas forrageiras vem crescendo, em consorciação com poáceas ou exclusiva (bancos de proteínas), entre as quais Stylosanthes capitata Swartz. tem se destacado. Porém, sua utilização comercial tem sido limitada, em decorrência da antracnose, causada pelo fungo Colletotrichum gloeosporioides. Este trabalho teve como objetivo identificar genótipos de $S$. capitata com alto grau de resistência à antracnose. O trabalho foi desenvolvido na Embrapa Gado de Corte, de 2012 a 2014. Inicialmente, semearam-se 30 acessos de S. capitata em casa de vegetação, mantendo-se apenas uma planta por recipiente, onde estas permaneceram durante sete semanas até a realização da inoculação. Em delineamento de blocos ao acaso, em esquema fatorial (30 acessos do hospedeiro $\mathrm{x}$ quatro isolados do patógeno), com 10 repetições, conduziram-se dois experimentos, em épocas diferentes. Os isolados monospóricos de $C$. gloeosporioides (GC2, GC20, GC672 e GC722) foram selecionados com base na sua representatividade das raças fisiológicas mais frequentes no
Brasil. Tais isolados foram inoculados com suspensões de $10^{6}$ conídios $/ \mathrm{mL}$ nos acessos hospedeiros. Baseado no grau de resistência ao patógeno, os acessos foram classificados como imune a altamente suscetível. No campo, em experimento em blocos ao acaso com quatro repetições, avaliaram-se a severidade da doença em 44 acessos da leguminosa. Dentre os genótipos inoculados, nos dois experimentos, os acessos GC1081, GC1087, GC1090, GC1094, GC1173 e GC2298 comportaram-se como resistentes a todos os isolados do patógeno estudados. Os isolados GC2 e GC672 foram os mais agressivos, independentemente do acesso do hospedeiro. Os resultados do experimento de campo evidenciaram a variabilidade genética do germoplasma estudado quanto à resistência a essa doença. No entanto, não foi possível selecionar acessos resistentes ao patógeno. Em tais condições, pode ocorrer nova variação físiológica do patógeno, mais agressiva que aquelas artificialmente inoculadas. Temperatura e umidade relativa médias de $22-26^{\circ} \mathrm{C}$ e $77 \%$ UR, respectivamente, proporcionaram condições adequadas para a evolução da doença no campo.

Palavras-chave: Colletotrichum gloeosporioides, leguminosas forrageiras, resistência.

\section{ABSTRACT}

Falco, J.S.; Fernandes, C.D.; Verzignassi, J.R.; Mallmann, G.; Queiróz, C.A.; Chagas, H.A.; Batista, M.V.; Quetez, F.A. Reaction of Stylosanthes capitata genotypes to anthracnose. Summa Phytopathologica, v.42, n.2, p.140-148, 2016.

Brazil has the largest commercial cattle herd in the world, based on the use of pastures. Currently, the use of forage legumes has been increasing, in association with grasses or exclusive (protein banks), among which Stylosanthes capitata Swartz must be highlighted. However, their commercial use has been limited due to anthracnose, caused by the fungus Colletotrichum gloeosporioides. This study aimed to identify genotypes of $S$. capitata with high degree of resistance to anthracnose. The study was carried out at Embrapa Beef Cattle, from 2012 to 2014. Initially, thirty S. capitata accessions were sown in a greenhouse, keeping just one plant per pot, where they remained for seven weeks until inoculation. In a randomized block design, factorial arrangement (30 host accessions $\mathrm{x}$ 4 pathogen isolates), and 10 replicates, two experiments were conducted at different times. The single spore isolates of C. gloeosporioides (GC2, GC20, GC672 and GC722) were selected based on their representativeness of the most frequent physiological races in Brazil. These isolates were inoculated with suspensions of $10^{6}$ conidia $/ \mathrm{mL}$ in host accessions. Based on the degree of resistance to the pathogen, the accessions were classified from immune to highly susceptible. In the field, in a randomized block experiment, with four replicates, the disease severity was evaluated on 44 accessions of the legume. Among the inoculated genotypes in both trials, the accessions GC1081, GC1087, GC1090, GC1094, GC 1173 and GC2298 behaved as resistant to all isolates of the studied pathogen. GC2 and GC672 were the most aggressive isolates, regardless of the host accession. Results of the field experiment evidenced the genetic variability of the studied germplasm for resistance to this disease. However, it was not possible to select accessions resistant to the pathogen. Under such conditions, a new physiological variation of the pathogen can occur, more aggressive than the artificially inoculated ones. Average temperature and relative humidity of $22-26^{\circ} \mathrm{C}$ and $77 \%$, respectively, provided appropriate conditions for the disease evolution in the field.

Keywords: Colletotrichum gloeosporioides, forage legumes, resistance. 
O Brasil detém o maior rebanho bovino comercial do mundo, com cerca de 212,8 milhões de cabeças (21), sendo superado apenas pela Índia, representado por 282 milhões de cabeças (22). O País é o segundo maior produtor e líder de exportação de carne bovina do mundo (1).

A pecuária brasileira está baseada quase que exclusivamente na utilização de pastagens (1), cuja área é de cerca de 174 milhões de hectares (20), sendo aproximadamente $40 \%$ dessa área localizada na região centro-oeste, a qual mais se destaca na pecuária brasileira (20).

Além das gramíneas forrageiras, as leguminosas, especialmente Stylosanthes spp. Swartz., têm se destacado nos sistemas pastoris, em virtude de sua alta capacidade de fixar biologicamente o nitrogênio atmosférico por meio da associação de suas raízes com bactérias Rhizobium spp. (32;18).

Dentre as diversas espécies de Stylosanthes com grande potencial para uso em consorciação com gramíneas tropicais destacam-se os genótipos de $S$. capitata, devido à sua adaptação a solos ácidos e de baixa fertilidade natural, resistência ao pisoteio, boa palatabilidade e boa produtividade de sementes $(38 ; 16)$. No entanto, sua utilização comercial tem sido limitada, em decorrência da sua suscetibilidade a algumas doenças, sendo a antracnose o agente biótico mais importante, reduzindo a produtividade $(14 ; 10 ; 16)$, a persistência e, consequentemente, a utilização dessa leguminosa em vários países, sobretudo nas Américas do Sul e Central (24).

O agente etiológico da antracnose é o fungo Colletotrichum gloeosporioides (Penz.) Penz \& Sacc., forma anamórfica de Glomerella cingulata (Stonem.) Spauld. \& Scherenk, o qual apresenta ampla variabilidade genética, sobretudo em seus centros de origem e diversidade $(7 ; 41)$. Sendo Stylosanthes spp. planta nativa das Américas, alguns estudos revelaram a existência de grande variabilidade de agressividade de isolados de $C$. gloeosporioides (7). Desta forma, vêm sendo realizados estudos de identificação de genes de resistência do hospedeiro e de agressividade do patógeno $(9 ; 24)$ para auxiliar nos programas de melhoramento da leguminosa para resistência à doença.

Os sintomas da doença em $S$. capitata são caracterizados pela ocorrência de pontuações e lesões marrom-claras a cinzas e margens escuras em caules, folíolos e inflorescências e, em alto grau de infecção, provoca desfolha severa de plantas suscetíveis, levandoas à morte $(6 ; 25)$. A doença é mais severa na época das chuvas, pois são necessárias condições quentes e úmidas para que ocorra a infecção, cujas condições ideais são temperatura variando entre 20 e $34^{\circ} \mathrm{C}$ e umidade acima de $95 \%$ (30).

Dessa forma, para os programas de melhoramento genético de Stylosanthes spp. considera-se importante a identificação de fontes de resistência de genótipos à antracnose, por ser prática, eficiente e de reduzido impacto na natureza (29). Entretanto, a durabilidade desta resistência dependerá de vários fatores, como o tipo de resistência, a variabilidade genética do patógeno, o ciclo da cultura, a extensão de cultivo da variedade, a ocorrência de raças fisiológicas, entre outros (34).

Sendo S. capitata espécie nativa do Brasil e Venezuela (33), Lenné et al. (26) recomendaram que a seleção de acessos desta espécie para resistência à $C$. gloeosporioides deve ser realizada em seus centros de origem, pois esta será mais eficiente, em virtude da maior variabilidade genética do agente etiológico.

Os mecanismos de resistência de plantas a patógenos são usualmente de natureza química, podendo manifestar-se de diferentes modos quanto à estabilidade e à especificidade (7). Conforme sua característica, a resistência pode ser classificada como resistência vertical ou horizontal (41). Em Stylosanthes spp., estudos de resistência à antracnose revelaram tanto a presença de herança quantitativa (19), como também a qualitativa (5). No entanto, Fernandes (16) sugere em seu trabalho a resistência horizontal como sendo uma das melhores formas de viabilizar o cultivo comercial dessa fabácea.

Este trabalho teve como objetivo identificar genótipos de Stylosanthes capitata com resistência à antracnose.

\section{MATERIAL E MÉTODOS}

O trabalho foi realizado nas dependências do Centro Nacional de Pesquisa de Gado de Corte (Embrapa Gado de Corte), em Campo Grande-MS, no período de dezembro de 2012 a fevereiro de 2014.

Reação de acessos de $S$. capitata a diferentes isolados de $C$. gloeosporioides

Avaliaram-se a reação de 30 acessos de $S$. capitata, oriundos do banco ativo de germoplasma da Embrapa Gado de Corte, à antracnose, a partir da inoculação de quatro isolados de Colletotrichum gloeosporioides (GC2, GC20, GC672 e GC772), originários de Campo Grande-MS (GC2 e GC672), Planaltina-DF (GC20) e Chapadão do Sul-MS (GC772), definidos por Fernandes (16) como representativos das principais raças do patógeno ocorrentes no Brasil.

As sementes dos acessos foram escarificadas e semeadas em casa de vegetação, em bandejas plásticas dotadas de recipientes com cerca de $100 \mathrm{~mL}$ cada, contendo mistura de solo e areia lavada, na proporção de 1:1, adubado com a formulação 10-10-10. Após a realização do desbaste, manteve-se apenas uma planta por recipiente. As plantas permaneceram em casa de vegetação até sete semanas de idade, quando apresentaram 5-6 folhas definitivas, ocasião em que se realizou a inoculação. Durante o período em casa de vegetação foram efetuadas adubações quinzenais e controle de pragas.

Para a realização das inoculações artificiais, utilizaram-se isolados monospóricos de C. gloeosporioides, os quais foram cultivados por 10 dias em meio de cultura de aveia-ágar, mantido em estufa $\mathrm{BOD}$, a $27^{\circ} \mathrm{C}$ e fotoperíodo de 12 horas de luz/12 horas de escuro, conforme recomendações de Fernandes et al. (15). Após a incubação, colônias esporuladas do patógeno tiveram seus conídios suspensos em água estéril, onde a concentração foi ajustada para $10^{6}$ conídios/mL (24).

Os experimentos foram delineados em blocos casualizados, em esquema fatorial (30 acessos x quatro isolados), com 10 repetições. Foram realizadas inoculações em duas épocas ÉPOCA 1 - 20/05/2012 a 30/05/2012; ÉPOCA 2 - 22/05/2012 a 03/06/2012, contemplando dois grupos distintos dos acessos de $S$. capitata. Os acessos GC1086 e GC1094 (testemunhas suscetíveis) foram utilizados como tratamentos comuns nos dois experimentos visando-se posterior estudo da possibilidade de análise conjunta dos resultados da severidade de antracnose nos experimentos realizados nas duas épocas.

Os isolados do patógeno foram inoculados imediatamente após a preparação da suspensão de conídios e pulverizados em ambas as faces da folha até a cobertura completa das mesmas, sem haver escorrimento (17; 4). Após a inoculação, as plantas foram dispostas em câmara úmida $\left(100 \%\right.$ de umidade relativa) e temperatura de $28-30^{\circ} \mathrm{C}$, por 48 horas. Posteriormente, as plantas foram acomodadas em bancadas em sala climatizada, à mesma temperatura e iluminação natural, onde permaneceram até a avaliação da doença, 12 dias após a inoculação (7). 
Para a avaliação da severidade da antracnose nos genótipos estudados, utilizou-se a escala diagramática de notas de 0 (ausência de sintomas) a 9 (planta morta), conforme representação esquemática (Figura 1) (8). Posteriormente, os dados foram submetidos à análise de variância e teste de médias, usando-se, respectivamente, os procedimentos GLM do SAS (35) e Scott-Knott (12).

De acordo com o grau de resistência ao patógeno, os acessos foram classificados conforme Fernandes (16), baseado na severidade (SEV): imune $(\mathrm{SEV}=0)$; altamente resistente $(0<\mathrm{SEV} \leq 2)$; resistente $(2<$ SEV $\leq 4)$; suscetível $(4<\mathrm{SEV} \leq 7)$ e altamente suscetível $(\mathrm{SEV}>7)$.

Para análise estatística dos dados, as notas de severidade da doença (SEV.) foram transformadas para (SEV. $+0,01)^{0,5}$.

Todos os genótipos $S$. capitata foram avaliados novamente no período de 10 a 20 de junho de 2013 com os mesmos isolados de $C$. gloeosporioides, utilizando-se os mesmos métodos.

\section{Reação de acessos de $S$. capitata à antracnose em campo}

$\mathrm{O}$ delineamento experimental adotado foi em blocos casualizados com quatro repetições e os tratamentos representados por 44 acessos de $S$. capitata, oriundos do banco de germoplasma da Embrapa Gado de Corte.

O solo foi preparado com operações de grade pesada e de nivelamento. Cada parcela foi estabelecida em uma linha simples de três metros, semeando-se cada acesso de $S$. capitata com sementes previamente escarificadas mecanicamente, com taxa de semeadura de $1 \mathrm{~g}$ de sementes por metro linear. $\mathrm{O}$ espaçamento entre parcelas foi de $1 \mathrm{~m}$.

Após a semeadura, realizou-se monitoramento semanal da ocorrência da antracnose nas plantas e, com o surgimento dos primeiros sintomas da doença, iniciaram-se as avaliações da severidade, considerando-se as plantas em toda a linha de cada parcela do experimento. Cada avaliação foi realizada por dois avaliadores, buscando-se resultados mais precisos. Para tanto, utilizou-se a escala diagramática de notas, conforme Figura 1 (8).

As avaliações da antracnose foram realizadas semanalmente no período de fevereiro a abril de 2013 , totalizando oito avaliações. O término das avaliações deu-se em virtude das condições climáticas tornarem-se desfavoráveis à doença.

As notas de severidade da doença foram transformadas para $(\mathrm{SEV} .+0,01)^{0,5}$ para o cálculo da área abaixo da curva de progresso da doença (AACPD), conforme a fórmula:

$$
\mathrm{AACPD}=\sum_{i}^{n-1}\left(\frac{y_{i}+y_{i+1}}{2}\right) \cdot\left(t_{i+1}-t_{i}\right)
$$

onde, $\mathrm{n}$ é o número de avaliações realizadas no período e y é a severidade da antracnose nos tempos $t$ (37).

Os dados foram analisados utilizando-se o programa Genes versão 2007.0.0 (12) e as médias comparadas pelo teste de Scott e Knott a 5\% de probabilidade pelo mesmo Programa.

Durante a execução do experimento coletaram-se dados de precipitação, umidade relativa e de temperaturas máxima, média, mínima na área experimental, os quais foram registrados pela Estação Meteorológica da Embrapa Gado de Corte, localizada a cerca de $300 \mathrm{~m}$ do experimento.

Na mesma área experimental, em fevereiro de 2014, realizaramse duas novas avaliações da severidade da antracnose nos mesmos genótipos de Stylosanthes capitata, rebrotados após a estação de estiagem de 2013. A metodologia adotada foi a mesma utilizada nas primeiras avaliações.

\section{RESULTADOS DE DISCUSSÃO}

Reação de acessos de $S$. capitata a diferentes isolados de $C$. gloeosporioides

Em virtude dos ensaios terem sido efetuados em duas épocas distintas, analisou-se a severidade da antracnose causada por cada um dos isolados de C. gloeosporioides nas testemunhas GC1086 e GC1094, comuns a ambos os experimentos nas duas épocas. Conforme a Tabela 1, não houve significância para época de inoculação desses acessos de $S$. capitata, considerando-se os isolados de C. gloeosporioides CG2 e CG20. No entanto, com exceção do acesso GC1094, inoculado com o isolado CG672, houve efeito de época de inoculação na severidade. Com base nesses resultados, não foi possível a realização de análise conjunta dos experimentos e, desta forma, decidiu-se apresentar a análise dos resultados de inoculação dos acessos de $S$. capitata por época. Resultados semelhantes foram observados por Fernandes (16), ao avaliar diferentes experimentos de inoculação de $C$. gloeosporioides em genótipos de Stylosanthes spp. O referido autor explicou que tais resultados foram devidos a variações ambientais e/ou erros experimentais, não controlados durante a execução em duas diferentes épocas dos experimentos.

Tabela 1. Valores de F do efeito de épocas de inoculação expressos para severidade de antracnose em acessos de Stylosanthes capitata inoculados com isolados de Colletotrichum gloeosporioides em duas épocas de inoculação. Campo Grande - MS, 2013.

\begin{tabular}{ccccc}
\hline Acesso & \multicolumn{4}{c}{ Isolados $\left(\mathbf{N}^{\circ} \mathbf{G C}\right)^{*}$} \\
$\left(\mathrm{~N}^{\circ} \mathrm{GC}\right)^{*}$ & 2 & 20 & 672 & 722 \\
1086 & $0,72 \mathrm{NS}^{*}$ & $0,11 \mathrm{NS}$ & 5,23 & 29,78 \\
1094 & $0,04 \mathrm{NS}$ & $0,00 \mathrm{NS}$ & $0,58 \mathrm{NS}$ & 13,76 \\
\hline
\end{tabular}

*NS = Não significativo a $5 \%$ de probabilidade pelo teste $\mathrm{F}$.

Analisando-se os resultados da severidade da antracnose nos experimentos realizados em duas épocas distintas, verificaram-se diferenças significativas entre isolados do patógeno, hospedeiros e sua interação. Dessa forma, realizaram-se análises com os fatores acessos e isolados desdobrados (Tabelas 2 e 3). Os isolados CG2 e CG672 foram mais agressivos, independentemente do acesso e, de forma geral, CG20 foi menos agressivo para todos os acessos de $S$. capitata em ambas as épocas de inoculação.

Com base nos resultados da severidade da antracnose, causada pelos quatro isolados de $C$. gloeosporioides inoculados nos genótipos de $S$. capitata, categorizaram-se os acessos como imunes a altamente suscetíveis, conforme Fernandes (16). Nos dois experimentos realizados, somente os acessos GC1049, GC1081, GC1084, GC1087, GC1090, GC1094, GC1173, GC1182, GC1184 e GC2298 comportaram-se como resistentes a todos os isolados do patógeno. Os demais acessos foram suscetíveis ou altamente suscetíveis à, pelo menos, um isolado do fungo. Os resultados obtidos corroboram com aqueles de Marchi et al. (27), que também identificaram os genótipos de S. capitata, GC1081, GC1084 e GC1094, com resistência à antracnose.

Na Tabela 4 estão apresentados os resultados da repetição do experimento com novas inoculações. Em relação aos isolados do patógeno, foram observados resultados semelhantes aos experimentos anteriores e o isolado de C. gloeosporioides CG20 foi o menos agressivo. Alguns acessos, que se comportaram como resistentes nos ensaios anteriores, apresentaram maior grau de suscetibilidade neste 


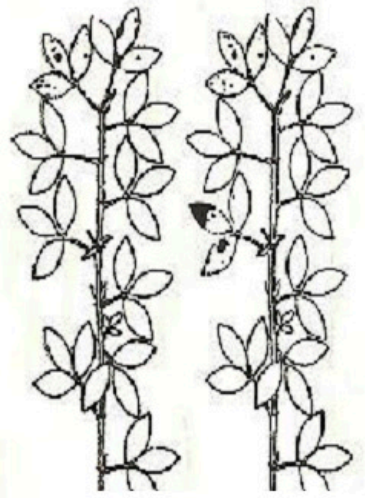

$1 \%{ }^{*}$

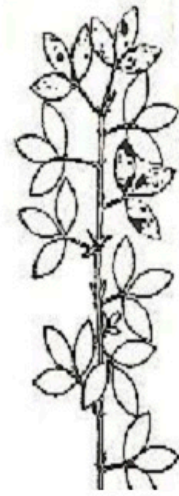

$4 \%$

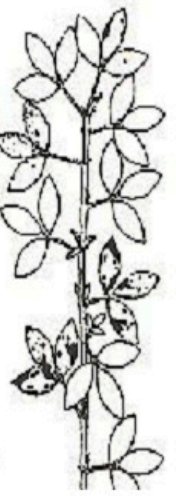

$6 \%$

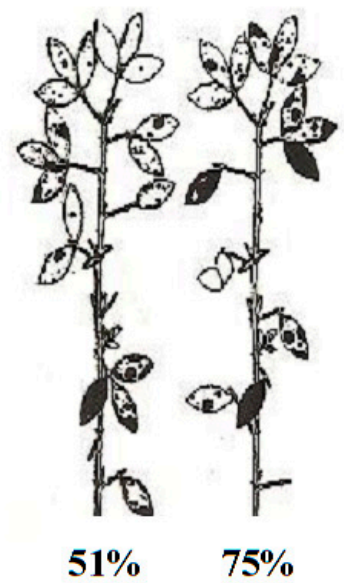

6

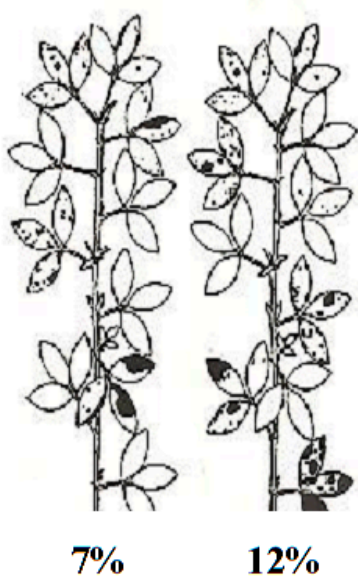

3

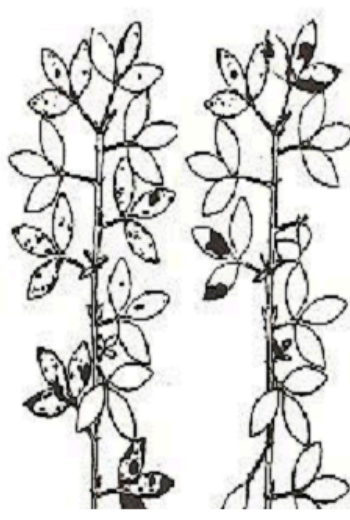

$13 \%$

$25 \%$

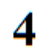

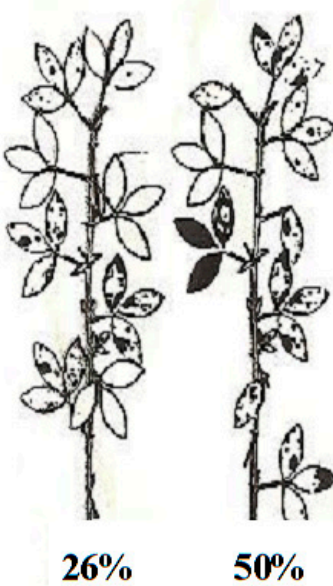

5

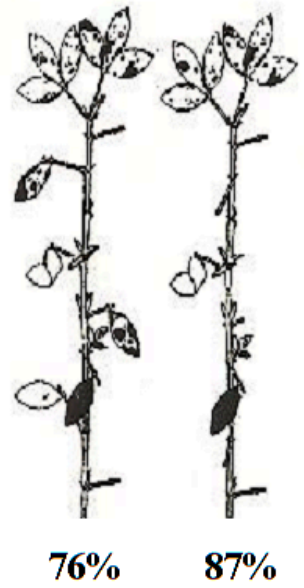

7

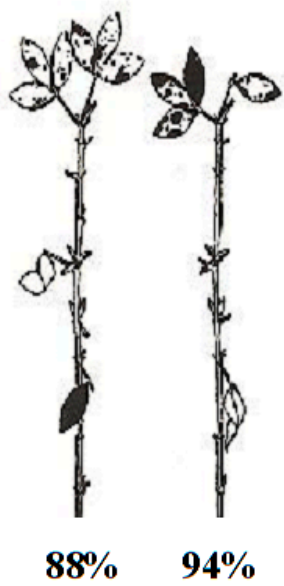

8

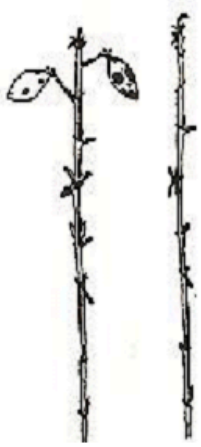

$95 \% \quad 100 \%$

Figura 1. Escala diagramática para avaliação da severidade da antracnose em plantas de Stylosanthes spp., expressa em percentagem de área foliar lesionada e desfolha (Chakraborty,1990). * Área foliar lesionada/desfolha; ** Classe de notas.

experimento, sendo classificados como suscetíveis a pelo menos um isolado do patógeno. Assim, somente os acessos GC1081, GC1087, GC1090, GC1094 e GC1173 mantiveram-se na categoria resistente $(2<\mathrm{SEV} \leq 4)$ a todos os isolados de $C$. gloeosporioides estudados. Resultados semelhantes foram obtidos por Botrel et al. (3), que identificaram somente $28 \%$ de acessos dessa fabácea resistentes à doença.

Neste trabalho, ficaram evidenciadas as variabilidades de agressividade de isolados de C. gloeosporioides, bem como do grau de resistência dos genótipos de $S$. capitata estudados. Chakraborty et al. (7) relataram que tal variabilidade de isolados do patógeno, obtidos de diversas regiões do Brasil, é fenômeno justificado pelo fato de o Brasil constituir o principal centro de origem e diversidade do estilosantes, onde o patógeno coevolui com o seu hospedeiro. Dessa forma, é de extrema relevância inoculações de isolados de C. gloeosporioides oriundos de diferentes origens, a fim de identificar fontes de resistência à antracnose.

\section{Reação de acessos de $S$. capitata à antracnose em campo}

A doença ocorreu em todos os acessos de $S$. capitata avaliados no campo (Tabela 5). Porém, foram observadas diferenças significativas $(\mathrm{P}<0,05$; teste $\mathrm{F})$ na severidade da doença, sendo possível a separação em dois agrupamentos, pelo teste Skott \& Knott, para a área abaixo da curva de progresso da doença (AACPD), cuja amplitude foi de 66,63 a 34,99 .

A antracnose foi mais severa em alguns acessos, indicando o local onde foram realizadas as avaliações como adequado no que se refere à população natural do patógeno.

Analisando-se os resultados da doença em abril/13 e fevereiro/14, observou-se que a maioria dos acessos de $S$. capitata estudados comportou-se como suscetível $(4<\mathrm{SEV} \leq 7)$ em pelo menos uma avaliação.

Na literatura há relatos que explicam a variabilidade da reação de acessos de $S$. capitata à antracnose, bem como a complexidade e diversidade da interação Stylosanthes spp. x C. gloeosporioides, onde a grande variabilidade genética do fungo é a principal causa da rápida seleção de raças virulentas $(23 ; 31)$. 
Tabela 2. Severidade de antracnose em acessos de Stylosanthes capitata inoculados com isolados de Colletotrichum gloeosporioides no Experimento 1 (20-30/05/2013). Campo Grande - MS, 2013.

\begin{tabular}{ccccc}
\hline Acesso & \multicolumn{4}{c}{ Isolados $\left(\mathbf{N}^{\circ} \mathbf{G C}\right)^{*}$} \\
\cline { 2 - 5 }$\left(\mathbf{N}^{\circ} \mathbf{G C}\right) *$ & $\mathbf{2}$ & $\mathbf{2 0}$ & $\mathbf{6 7 2}$ & $\mathbf{7 2 2}$ \\
\hline 2265 & $4,48^{* * *} \mathrm{Aa} * *$ & $0,07 \mathrm{Ca}$ & $2,13 \mathrm{Bb}$ & $4,54 \mathrm{Aa}$ \\
2266 & $4,53 \mathrm{Aa}$ & $0,13 \mathrm{Ba}$ & $4,42 \mathrm{Aa}$ & $4,61 \mathrm{Aa}$ \\
2298 & $4,00 \mathrm{Aa}$ & $0 \mathrm{Ca}$ & $2,04 \mathrm{Bb}$ & $4,00 \mathrm{Aa}$ \\
2268 & $4,24 \mathrm{Aa}$ & $0,03 \mathrm{Ca}$ & $3,27 \mathrm{Aa}$ & $2,12 \mathrm{Bb}$ \\
2299 & $4,43 \mathrm{Aa}$ & $0,03 \mathrm{Da}$ & $1,84 \mathrm{Bb}$ & $0,39 \mathrm{Cc}$ \\
2300 & $2,94 \mathrm{Aa}$ & $0,03 \mathrm{Ba}$ & $4,24 \mathrm{Aa}$ & $3,1 \mathrm{Ab}$ \\
1049 & $3,96 \mathrm{Aa}$ & $0 \mathrm{Ca}$ & $3,22 \mathrm{Aa}$ & $0,55 \mathrm{Bc}$ \\
1054 & $4,43 \mathrm{Aa}$ & $0,03 \mathrm{Ca}$ & $4,31 \mathrm{Aa}$ & $2,18 \mathrm{Bb}$ \\
1061 & $4,32 \mathrm{Aa}$ & $0,09 \mathrm{Ba}$ & $4,21 \mathrm{Aa}$ & $4,35 \mathrm{Aa}$ \\
1064 & $5,97 \mathrm{Aa}$ & $0,03 \mathrm{Ca}$ & $2,58 \mathrm{Bb}$ & $3,04 \mathrm{Bb}$ \\
1081 & $3,58 \mathrm{Aa}$ & $0 \mathrm{Ca}$ & $2,25 \mathrm{Bb}$ & $0,03 \mathrm{Cd}$ \\
1084 & $3,93 \mathrm{Aa}$ & $0 \mathrm{Da}$ & $2,14 \mathrm{Bb}$ & $0,33 \mathrm{Cc}$ \\
1086 & $4,78 \mathrm{Aa}$ & $0,04 \mathrm{Ba}$ & $4,32 \mathrm{Aa}$ & $4,21 \mathrm{Aa}$ \\
1087 & $0,07 \mathrm{Ab}$ & $0,07 \mathrm{Ca}$ & $3,13 \mathrm{Aa}$ & $0,45 \mathrm{Bc}$ \\
1090 & $3,93 \mathrm{Aa}$ & $0 \mathrm{Da}$ & $2,49 \mathrm{Bb}$ & $1,06 \mathrm{Cc}$ \\
1091 & $4,53 \mathrm{Aa}$ & $0,40 \mathrm{Ba}$ & $3,08 \mathrm{Aa}$ & $4,19 \mathrm{Aa}$ \\
1094 & $4,21 \mathrm{Aa}$ & $0,03 \mathrm{Ba}$ & $3,97 \mathrm{Aa}$ & $4,43 \mathrm{Aa}$ \\
\hline
\end{tabular}

* $\mathrm{N}^{\circ}$ de registro na Embrapa Gado de Corte.

**Médias seguidas pelas mesmas letras maiúsculas na linha e minúsculas na coluna não diferem entre si pelo teste de Scott-Knott a 5\% de probabilidade. Para análise estatística, as médias foram transformadas para $(\mathrm{sev}+0,01)^{0,5}$.

*** Escala diagramática de notas de 0-9, conforme Chakraborty et al., (1990).

A Figura 2 ilustra o progresso da antracnose em dois acessos de $S$. capitata, GC1054 e GC1059, suscetível e resistente à doença em campo, respectivamente, bem como as variáveis ambientais. Confrontando-se os dados de progresso da antracnose com temperatura, umidade relativa e precipitação (Figura 2), observou-se que as variáveis climáticas atuam sobre as diferentes fases do ciclo das relações patógeno-hospedeiro. Dessa forma, a infecção ocorreu a partir do final de fevereiro, quando a temperatura e a umidade relativa foram favoráveis ao desenvolvimento da doença (16).

Durante todo o período de avaliação, as temperaturas máxima, mínima e média foram, respectivamente, $28-32,16-22$ e $22-26^{\circ} \mathrm{C}$. Segundo Vale et al. (39), em geral, a temperatura é o fator do ambiente que mais influencia a incidência e severidade das doenças. Ainda, na Figura 2 (B) observa-se que, durante o período de avaliação, a umidade relativa média foi de aproximadamente $77 \%$, condição favorável ao progresso da doença, conforme verificado anteriormente por Fernandes (16). Também, as precipitações mais frequentes a partir do início de março (Figura 2C) contribuíram para o progresso da doença. De acordo com Davis et al. (13), elevadas precipitações reduzem a severidade de C. gloeosporioides. No entanto, nas condições experimentais, quando as chuvas mantiveram-se mais constantes, ou seja, até a oitava semana, a severidade da doença aumentou, confirmando a característica de C. gloeosporioides descrita por Vale et al. (39), de que esta é uma espécie fitopatogênica extremamente dependente da água, onde os respingos de chuva desempenham papel relevante na disseminação
Tabela 3. Severidade de antracnose em acessos de Stylosanthes capitata inoculados com isolados de Colletotrichum gloeosporioides no Experimento 2 (22/05/2013 a 03/06/2013). Campo Grande-MS, 2013.

\begin{tabular}{ccccc}
\hline Acesso & \multicolumn{4}{c}{ Isolados $\left(\mathbf{N}^{\circ} \mathbf{G C}\right)^{*}$} \\
\cline { 2 - 5 }$\left(\mathbf{N}^{\circ} \mathbf{G C}\right)^{*}$ & $\mathbf{2}$ & $\mathbf{2 0}$ & $\mathbf{6 7 2}$ & $\mathbf{7 2 2}$ \\
\hline $1086^{* * * *}$ & $4,44 * * * \mathrm{Ab}^{* *}$ & $0 \mathrm{Db}$ & $2,53 \mathrm{Bc}$ & $0,37 \mathrm{Cc}$ \\
$1094 * * *$ & $3,77 \mathrm{Ab}$ & $0,03 \mathrm{Cb}$ & $3,83 \mathrm{Ab}$ & $0,77 \mathrm{Bb}$ \\
1095 & $5,1 \mathrm{Aa}$ & $0,04 \mathrm{Bb}$ & $4,49 \mathrm{Aa}$ & $4,49 \mathrm{Aa}$ \\
1161 & $4,37 \mathrm{Ab}$ & $0,04 \mathrm{Cb}$ & $3,12 \mathrm{Ab}$ & $0,37 \mathrm{Bc}$ \\
1173 & $3,11 \mathrm{Ab}$ & $0,9 \mathrm{Ba}$ & $2,26 \mathrm{Ac}$ & $0,37 \mathrm{Bc}$ \\
1179 & $4,27 \mathrm{Ab}$ & $0,03 \mathrm{Cb}$ & $0,87 \mathrm{Bd}$ & $0,37 \mathrm{Bc}$ \\
1180 & $6,04 \mathrm{Aa}$ & $0,03 \mathrm{Cb}$ & $4,85 \mathrm{Aa}$ & $3,47 \mathrm{Ba}$ \\
1182 & $3,99 \mathrm{Ab}$ & $0,44 \mathrm{Ca}$ & $0,91 \mathrm{Bd}$ & $0,26 \mathrm{Cc}$ \\
1184 & $3,73 \mathrm{Ab}$ & $0 \mathrm{Cb}$ & $3,02 \mathrm{Ab}$ & $1,1 \mathrm{Bb}$ \\
1279 & $4,48 \mathrm{Ab}$ & $0 \mathrm{Cb}$ & $3,38 \mathrm{Ab}$ & $0,64 \mathrm{Bb}$ \\
1321 & $3,65 \mathrm{Ab}$ & $0 \mathrm{Bb}$ & $4,42 \mathrm{Aa}$ & $4,24 \mathrm{Aa}$ \\
1465 & $6,11 \mathrm{Aa}$ & $0 \mathrm{Bb}$ & $6,1 \mathrm{Aa}$ & $4,73 \mathrm{Aa}$ \\
1469 & $4,3 \mathrm{Ab}$ & $0 \mathrm{Cb}$ & $1,76 \mathrm{Bc}$ & $0,17 \mathrm{Cc}$ \\
2188 & $4,54 \mathrm{Ab}$ & $0,09 \mathrm{Bb}$ & $4,00 \mathrm{Ab}$ & $3,65 \mathrm{Aa}$ \\
2267 & $4,11 \mathrm{Ab}$ & $0 \mathrm{Bb}$ & $4,12 \mathrm{Ab}$ & $3,77 \mathrm{Aa}$ \\
\hline
\end{tabular}

* $\mathrm{N}^{\circ}$ de registro na Embrapa Gado de Corte.

**Médias seguidas pelas mesmas letras maiúsculas na linha e minúsculas na coluna não diferem entre si pelo teste de Scott-Knott a $5 \%$ de probabilidade. Para análise estatística, as médias foram transformadas para $(\operatorname{sev}+0,01)^{0,5}$.

*** Escala diagramática de notas de 0-9, conforme Chakraborty et al., (1990). ****Testemunhas suscetíveis

do patógeno, planta a planta.

A disponibilidade e a quantidade de inóculo do patógeno são fundamentais para a infecção, onde a eficiência dessa infecção irá depender de suas características de virulência e agressividade. Uma dessas características é a capacidade de realização de ciclos curtos de reprodução, podendo produzir várias gerações em uma única estação de cultivo (2). Sendo C. gloeosporioides um fungo policíclico, a curva de progresso da doença gerada no acesso suscetível GC1054 (Figura 2A) corrobora com Vale et al. (39), apresentando lento desenvolvimento em seus estádios iniciais, devido ao fato de poucas infecções ocorrerem neste período, mas uma rápida aceleração ocorreu assim que novos propágulos foram formados, aliado às condições ambientais favoráveis.

Em trabalho de campo realizado por Charchar et al. (10) com acessos de $S$. capitata, foram encontrados genótipos resistentes. Porém, em outro trabalho dos mesmos autores, os mesmos genótipos já haviam sido classificados como suscetíveis. Os autores atribuíram tais variações às alterações nas condições ambientais de realização dos experimentos.

Segovia (36) relata a importância do coeficiente de variação genético $(\mathrm{CVg})$, pois indica a possibilidade de se obter progresso genético satisfatório com a seleção. No entanto, a variabilidade genética dos genótipos estudados ( $\mathrm{CVg}$ ) (Tabela 5) foi relativamente pequena para resistência à antracnose, dados estes que corroboram com aqueles obtidos por Fernandes (16), quando estudou a reação de progênies de $S$. capitata à referida doença.

A herdabilidade $(\mathrm{H})$, com base na média dos indivíduos 
$\mathbf{A}$

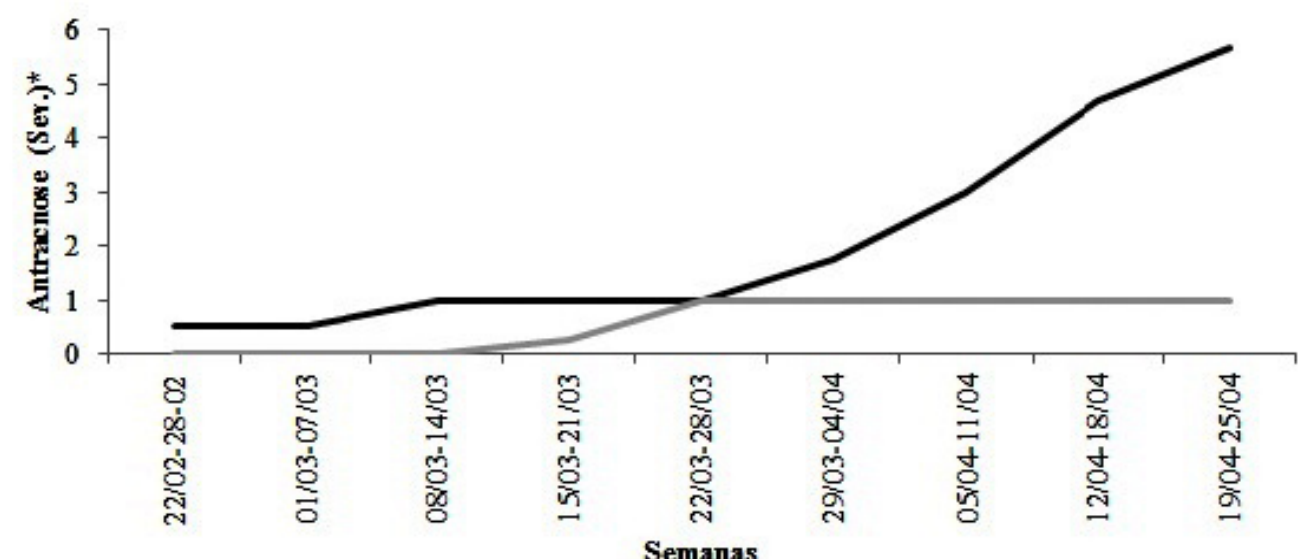

B

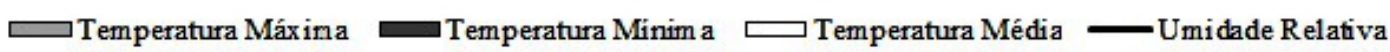

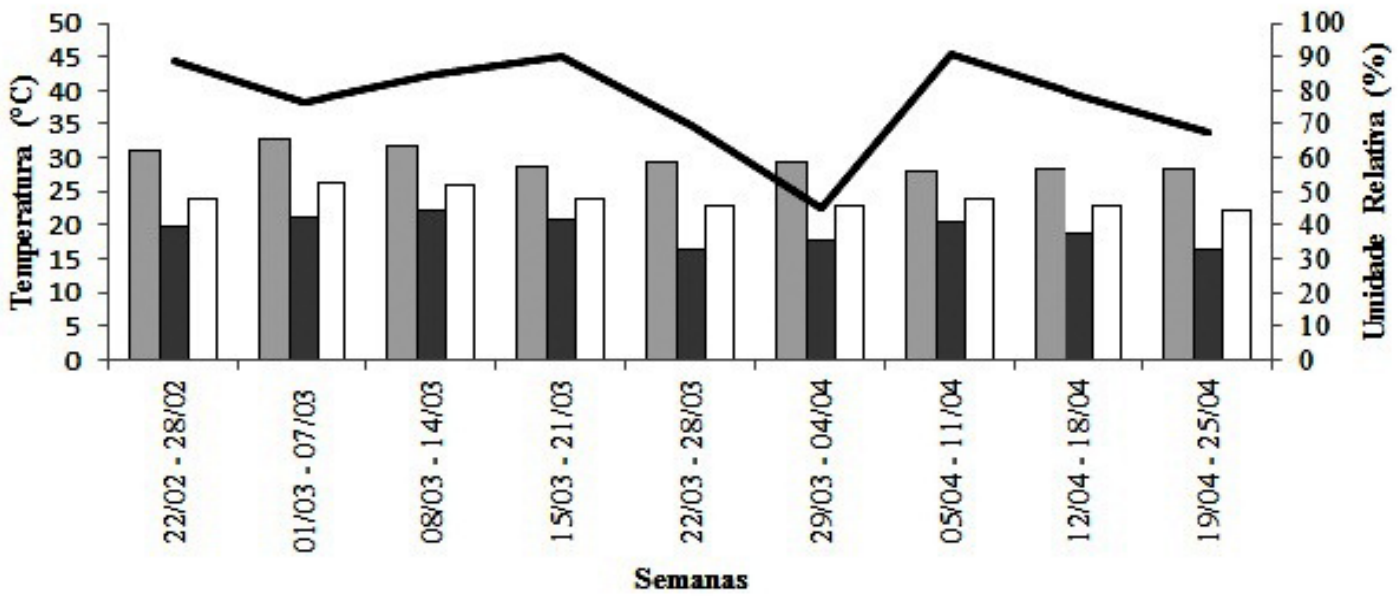

C

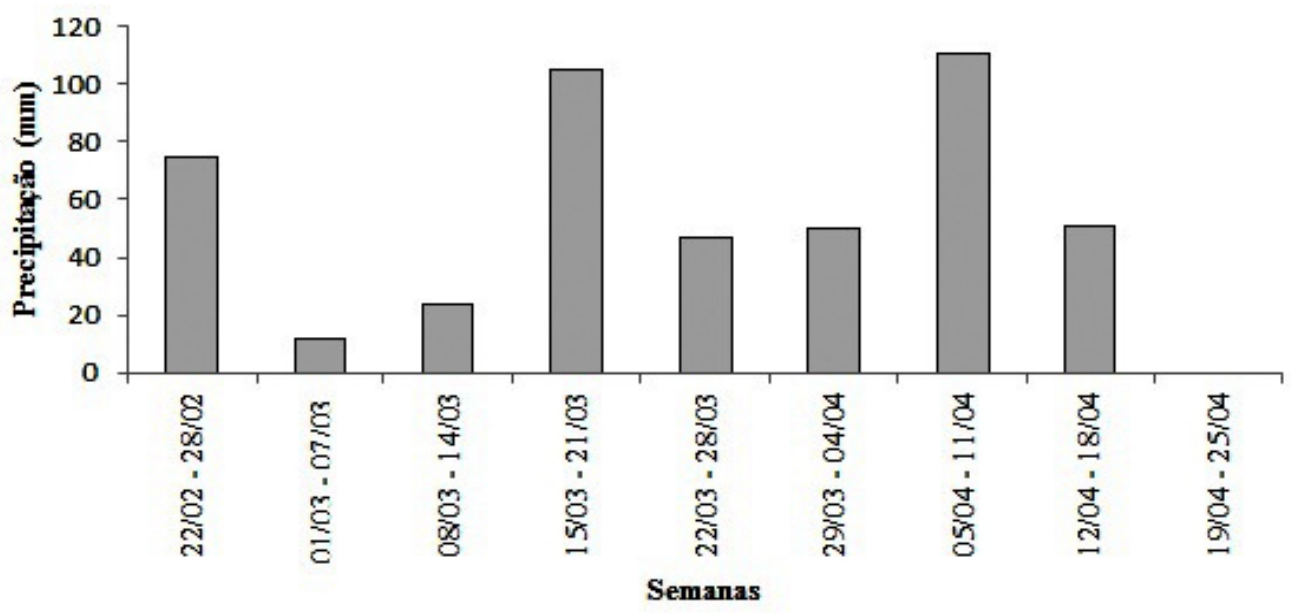

Figura 2. Evolução da severidade de antracnose em acessos de Stylosanthes capitata resistente (GC1059) e suscetível (GC1054)(A) sob condições naturais de Temperatura e Umidade Relativa(B) e Precipitação(C). Campo Grande - MS, 2013.

* Escala diagramática de notas de 0-9, conforme Chakraborty et al. (1990). 
Tabela 4. Severidade de antracnose em acessos de Stylosanthes capitata inoculados com isolados de Colletotrichum gloeosporioides (10-21/06) Campo Grande - MS, 2013.

\begin{tabular}{|c|c|c|c|c|}
\hline \multirow{2}{*}{$\begin{array}{c}\text { Acesso } \\
\left(\mathrm{N}^{\circ} \mathrm{GC}\right)^{*}\end{array}$} & \multicolumn{4}{|c|}{ Isolados ( $\left.\mathbf{N}^{\circ} \mathbf{G C}\right) *$} \\
\hline & 2 & 20 & 672 & 722 \\
\hline 2265 & $2,09 \mathrm{Ac}^{* *}$ & $0,31 \mathrm{Bc}$ & 2,9 Aa & $2,11 \mathrm{Ab}$ \\
\hline 2266 & $2,6 \mathrm{Ab}$ & $0,19 \mathrm{Bc}$ & $3,21 \mathrm{Aa}$ & $3,52 \mathrm{Aa}$ \\
\hline 2298 & $4,35 \mathrm{Aa}$ & $0,06 \mathrm{Bc}$ & $3,82 \mathrm{Aa}$ & 3,62 Aa \\
\hline 2268 & 3,99 Аа & $0,07 \mathrm{Cc}$ & $1,02 \mathrm{Bb}$ & $1,15 \mathrm{Bb}$ \\
\hline 2299 & $3,84 \mathrm{Aa}$ & $0,04 \mathrm{Cc}$ & $0,92 \mathrm{Bb}$ & $2,48 \mathrm{Ab}$ \\
\hline 2300 & $4,05 \mathrm{Aa}$ & $0,05 \mathrm{Bc}$ & $3,54 \mathrm{Aa}$ & $2,96 \mathrm{Aa}$ \\
\hline 1049 & $4,23 \mathrm{Aa}$ & $0,72 \mathrm{Bb}$ & $3,43 \mathrm{Aa}$ & $4,65 \mathrm{Aa}$ \\
\hline 1054 & $3,71 \mathrm{Aa}$ & $0,56 \mathrm{Bb}$ & $2,8 \mathrm{Aa}$ & $1,91 \mathrm{Ab}$ \\
\hline 1061 & $3,79 \mathrm{Aa}$ & $0,55 \mathrm{Cb}$ & $3,54 \mathrm{Aa}$ & $2,16 \mathrm{Bb}$ \\
\hline 1064 & $2,85 \mathrm{Ab}$ & $0,13 \mathrm{Bc}$ & $2,34 \mathrm{Ab}$ & $2,92 \mathrm{Aa}$ \\
\hline 1081 & $2 \mathrm{Bc}$ & $1,27 \mathrm{Bb}$ & $2,84 \mathrm{Aa}$ & $3,4 \mathrm{Aa}$ \\
\hline 1084 & $4,41 \mathrm{Aa}$ & $0,96 \mathrm{Cb}$ & $2,07 \mathrm{Bb}$ & 3,23 Aa \\
\hline$* * * * 1086$ & $5,34 \mathrm{Aa}$ & $0,33 \mathrm{Bc}$ & $3,71 \mathrm{Aa}$ & $3,72 \mathrm{Aa}$ \\
\hline 1087 & $1,25 \mathrm{Ac}$ & $0,34 \mathrm{Bc}$ & $1,36 \mathrm{Ab}$ & $2,04 \mathrm{Ab}$ \\
\hline 1090 & $0,7 \mathrm{Bc}$ & $0,21 \mathrm{Bc}$ & $3,22 \mathrm{Aa}$ & $2,48 \mathrm{Ab}$ \\
\hline 1091 & $2,8 \mathrm{Ab}$ & $0,28 \mathrm{Cc}$ & $1,58 \mathrm{Bb}$ & $3,87 \mathrm{Aa}$ \\
\hline$* * * * 1094$ & $3,81 \mathrm{Aa}$ & $0,2 \mathrm{Cc}$ & $2,3 \mathrm{Bb}$ & 3,99 Aa \\
\hline 1095 & 4,95 Aa & $0,88 \mathrm{Bb}$ & $4,11 \mathrm{Aa}$ & $2,96 \mathrm{Aa}$ \\
\hline 1161 & $2,62 \mathrm{Ab}$ & $0,16 \mathrm{Bc}$ & $2,85 \mathrm{Aa}$ & $2,24 \mathrm{Ab}$ \\
\hline 1173 & $3,59 \mathrm{Aa}$ & $1,14 \mathrm{Bb}$ & $1,83 \mathrm{Bb}$ & $1,68 \mathrm{Bb}$ \\
\hline 1179 & $3,06 \mathrm{Ab}$ & $0,28 \mathrm{Cc}$ & $1,52 \mathrm{Bb}$ & $3,26 \mathrm{Aa}$ \\
\hline 1180 & $2,89 \mathrm{Ab}$ & $0,21 \mathrm{Bc}$ & 3,63 Aa & $2,69 \mathrm{Ab}$ \\
\hline 1182 & $3,85 \mathrm{Aa}$ & $3,01 \mathrm{Aa}$ & $4,01 \mathrm{Aa}$ & $3,54 \mathrm{Aa}$ \\
\hline 1184 & $3,63 \mathrm{Aa}$ & $0,43 \mathrm{Bc}$ & $4,07 \mathrm{Aa}$ & $3,85 \mathrm{Aa}$ \\
\hline 1279 & 4,93 Aa & $0,71 \mathrm{Bb}$ & $3,87 \mathrm{Aa}$ & $1,58 \mathrm{Bb}$ \\
\hline 1321 & $4,49 \mathrm{Aa}$ & $1,02 \mathrm{Bb}$ & $3,87 \mathrm{Aa}$ & 3,52 Aa \\
\hline 1465 & $4,82 \mathrm{Aa}$ & $0,31 \mathrm{Bc}$ & $3,59 \mathrm{Aa}$ & $4,2 \mathrm{Aa}$ \\
\hline 1469 & $1,4 \mathrm{Bc}$ & $0,16 \mathrm{Cc}$ & $2,86 \mathrm{Aa}$ & $4,07 \mathrm{Aa}$ \\
\hline 2188 & $4,24 \mathrm{Aa}$ & $0,8 \mathrm{Bb}$ & $4,47 \mathrm{Aa}$ & 4,3 Aa \\
\hline 2267 & $1,38 \mathrm{Ac}$ & $0,09 \mathrm{Bc}$ & $2,51 \mathrm{Aa}$ & $2,4 \mathrm{Ab}$ \\
\hline
\end{tabular}

* $\mathrm{N}^{\circ}$ de registro na Embrapa Gado de Corte.

**Médias seguidas pelas mesmas letras maiúsculas na linha e minúsculas na coluna não diferem entre si pelo teste de Scott-Knott a 5\% de probabilidade. Para análise estatística, as médias foram transformadas para $(\operatorname{sev}+0,01)^{0,5}$. *** Escala diagramática de notas de 0-9, conforme Chakraborty et al. (1990). ****Testemunhas suscetíveis

(Tabela 5) para todas as avaliações da doença, apresentou valores expressivos. De acordo com Marchioro et al. (28) e Cruz; Carneiro (11), a herdabilidade representa o efeito cumulativo de todos os locos que afetam determinado caráter e a magnitude dessa variável indica a probabilidade de ganho de seleção em programas de melhoramento genético.

Assim, o desenvolvimento do presente trabalho permitiu a verificação da grande variabilidade dos acessos de Stylosanthes capitata
Tabela 5. Severidade de antracnose em acessos de Stylosanthes capitata sob infecção natural, expressas pela área abaixo da curva de progresso da doença (AACPD) no período de fevereiro a abril/13, e severidade máxima encontrada em duas ocasiões abril/13 e fevereiro/14 em Campo Grande-MS

\begin{tabular}{|c|c|c|c|}
\hline \multirow{2}{*}{$\begin{array}{l}\text { Acessos } \\
\left(\mathrm{N}^{\circ} \mathrm{GC}\right)^{*}\end{array}$} & \multirow[t]{2}{*}{ AACPD } & \multicolumn{2}{|c|}{ Severidade Máxima } \\
\hline & & Abril/13 & Fev./14 \\
\hline 1054 & $66,63 \mathrm{a}^{* *}$ & $5,65 \mathrm{a}$ & $6,20 \mathrm{~b}$ \\
\hline 1081 & $65,20 \mathrm{a}$ & $4,11 \mathrm{a}$ & $7,00 \mathrm{~b}$ \\
\hline 2162 & $60,94 \mathrm{a}$ & $4,96 \mathrm{a}$ & $5,50 \mathrm{a}$ \\
\hline 1086 & $60,14 \mathrm{a}$ & $3,64 \mathrm{~b}$ & $5,70 \mathrm{a}$ \\
\hline 1180 & $60,02 \mathrm{a}$ & $3,52 \mathrm{~b}$ & $5,70 \mathrm{a}$ \\
\hline 1095 & 59,03 a & $4,48 \mathrm{a}$ & $5,50 \mathrm{a}$ \\
\hline 1049 & $56,91 \mathrm{a}$ & $3,87 \mathrm{~b}$ & $6,20 \mathrm{~b}$ \\
\hline 1184 & $55,58 \mathrm{a}$ & $5,19 \mathrm{a}$ & $6,20 \mathrm{~b}$ \\
\hline 1064 & $54,76 \mathrm{a}$ & $4,66 \mathrm{a}$ & $6,00 \mathrm{~b}$ \\
\hline 2300 & $54,56 \mathrm{a}$ & $3,87 \mathrm{~b}$ & $6,00 \mathrm{~b}$ \\
\hline 2267 & $52,32 \mathrm{~b}$ & $4,66 \mathrm{a}$ & $6,20 \mathrm{~b}$ \\
\hline 1084 & $51,28 \mathrm{~b}$ & $1,65 \mathrm{~d}$ & $5,00 \mathrm{a}$ \\
\hline 1178 & $51,19 \mathrm{~b}$ & $3,56 \mathrm{~b}$ & $5,50 \mathrm{a}$ \\
\hline 1061 & $50,93 \mathrm{~b}$ & $4,66 \mathrm{a}$ & $5,50 \mathrm{a}$ \\
\hline 1096 & $50,51 \mathrm{~b}$ & $3,52 \mathrm{~b}$ & $5,70 \mathrm{a}$ \\
\hline 1510 & $50,30 \mathrm{~b}$ & $158 \mathrm{~d}$ & $5,20 \mathrm{a}$ \\
\hline 2265 & $49,94 \mathrm{~b}$ & $2,42 \mathrm{c}$ & $6,00 \mathrm{~b}$ \\
\hline 1279 & $49,57 \mathrm{~b}$ & $3,99 \mathrm{~b}$ & $6,00 \mathrm{~b}$ \\
\hline 1087 & $49,51 \mathrm{~b}$ & $3,56 \mathrm{~b}$ & $5,20 \mathrm{~b}$ \\
\hline 2268 & $49,29 \mathrm{~b}$ & $3,99 \mathrm{~b}$ & $5,50 \mathrm{a}$ \\
\hline 2302 & $48,90 \mathrm{~b}$ & $1,45 \mathrm{~d}$ & - \\
\hline 1050 & $48,47 \mathrm{~b}$ & $4,70 \mathrm{a}$ & $6,20 \mathrm{~b}$ \\
\hline 2266 & $48,25 \mathrm{~b}$ & $3,19 \mathrm{~b}$ & $6,20 \mathrm{~b}$ \\
\hline 1094 & $47,85 \mathrm{~b}$ & $4,96 \mathrm{a}$ & $3,20 \mathrm{a}$ \\
\hline 1161 & $47,61 \mathrm{~b}$ & $2,91 \mathrm{~b}$ & $5,20 \mathrm{a}$ \\
\hline 1090 & $47,42 \mathrm{~b}$ & $4,48 \mathrm{a}$ & $6,00 \mathrm{~b}$ \\
\hline 2298 & $46,77 \mathrm{~b}$ & $3,95 \mathrm{~b}$ & $5,50 \mathrm{a}$ \\
\hline 1179 & $46,70 \mathrm{~b}$ & $1,29 \mathrm{~d}$ & $5,20 \mathrm{a}$ \\
\hline 1181 & $46,52 \mathrm{~b}$ & $1,45 \mathrm{~d}$ & $6,20 \mathrm{~b}$ \\
\hline 1173 & $45,01 \mathrm{~b}$ & $2,01 \mathrm{c}$ & $5,50 \mathrm{a}$ \\
\hline 1321 & $44,59 \mathrm{~b}$ & $1,58 \mathrm{~d}$ & $5,50 \mathrm{a}$ \\
\hline 1170 & $44,49 \mathrm{~b}$ & $0,99 \mathrm{~d}$ & $5,70 \mathrm{a}$ \\
\hline 1466 & $44,24 \mathrm{~b}$ & $2,91 \mathrm{~b}$ & $6,20 \mathrm{~b}$ \\
\hline 1469 & $44,15 \mathrm{~b}$ & $3,27 \mathrm{~b}$ & $6,50 \mathrm{~b}$ \\
\hline 1071 & $44,09 \mathrm{~b}$ & $2,58 \mathrm{c}$ & $5,20 \mathrm{a}$ \\
\hline 1091 & $43,72 \mathrm{~b}$ & $4,70 \mathrm{a}$ & $6,00 \mathrm{~b}$ \\
\hline 1157 & $42,97 \mathrm{~b}$ & $2,88 \mathrm{~b}$ & $6,50 \mathrm{~b}$ \\
\hline 1465 & $42,77 \mathrm{~b}$ & $2,01 \mathrm{c}$ & $6,70 \mathrm{~b}$ \\
\hline 2188 & $42,09 \mathrm{~b}$ & $4,32 \mathrm{a}$ & $6,00 \mathrm{~b}$ \\
\hline 2299 & $41,93 \mathrm{~b}$ & $3,45 \mathrm{~b}$ & $6,00 \mathrm{~b}$ \\
\hline 1467 & $41,04 \mathrm{~b}$ & $2,68 \mathrm{~b}$ & - \\
\hline 2301 & $38,95 \mathrm{~b}$ & $0,99 \mathrm{~d}$ & $6,70 \mathrm{~b}$ \\
\hline 1182 & $35,65 \mathrm{~b}$ & $1,31 \mathrm{~d}$ & $5,70 \mathrm{a}$ \\
\hline 1059 & $34,99 \mathrm{~b}$ & $0,99 \mathrm{~d}$ & - \\
\hline $\begin{array}{c}\text { Coeficiente de variação } \\
(\%)\end{array}$ & 19,57 & 16,22 & 6,41 \\
\hline $\begin{array}{c}\text { Herdabilidade }(\mathrm{H})- \\
\text { médias }(\%)\end{array}$ & 53,96 & 87,13 & 40,52 \\
\hline $\begin{array}{l}\text { Coeficiente de variação } \\
\text { genético }(\mathrm{CVg}) \text { - } \\
\text { médias }(\%)\end{array}$ & 10,59 & 21,11 & 5,18 \\
\hline
\end{tabular}

* $\mathrm{N}^{\circ}$ de registro na Embrapa Gado de Corte.

** Médias seguidas pela mesma letra minúscula na coluna, não diferiram entre si, pelo teste de Scott- Knott a 5\% de probabilidade. Para análise estatística, as médias foram transformadas para $(\operatorname{sev}+0,01)^{0,5}$. 
estudados quanto à resistência à antracnose. Ainda, sob inoculações artificiais, os genótipos GC1081, GC1087, GC1090, GC1094, GC1173 e GC2298 apresentaram os maiores graus de resistência à doença. Esses mesmos genótipos, em infecção natural no campo, comportaramse como suscetíveis à antracnose, demonstrando a importância da avaliação sob condições controladas aliada à infecção natural em campo. A suscetibilidade ocorreu em função, possivelmente, de novas variações fisiológicas do patógeno, mais agressivos que aqueles inoculados artificialmente. As condições de temperatura média de 22$26^{\circ} \mathrm{C}$ e umidade relativa acima de $77 \%$ contribuíram para a evolução da doença.

\section{AGRADECIMENTOS}

Embrapa Gado de Corte, Universidade Estadual de Mato Grosso do Sul, Capes, CNPq, Fundect, Unipasto e Fundapam.

\section{REFERÊNCIAS}

1. Almeida, R. G.; Andrade, C. M. S.; Paciullo, D. S. C.; Fernandes, P. C. C.; Cavalcante, A. C. R.; Barbosa, R. A.; Valle, C. B. Brazilian agroforestry systems for cattle and sheep. Tropical Grasslands, Cali. v.1, p.175-183. 2013.

2. Amorim, L.; Rezende, J.A.M. \& Bergamin Filho, A. Manual de Fitopatologia: Princípios e Conceitos. 4. ed. São Paulo: Agronômica Ceres, 2011. $704 \mathrm{p}$.

3. Botrel, M.A.; Alvim, M.J.; Xavier, D.F.; Salvat, J.A. Avaliações agronômicas de acessos de Stylosanthes capitata. Pesquisa Agropecuária Brasileira, Brasília, v.16, n.9, p.1415-1421, 1991.

4. Cameron, P.F.; Irwin, J.A.G.; O’Brien, R.G. Variability in isolates of Colletotrichum gloeosporioides causing anthracnose diseases of Stylosanthes species. Aust. J. Exp. Agric. v.25, p.444-449, 1985.

5. Chakraborty, S. \& Billard, L. Quantitative relationships between Colletotrichum gloeosporioides infection of Stylosanthes scabra and weather under field conditions. Plant Pathology, London, v.44, n. 1, p.63-72, 1995.

6. Chakraborty, S.; Cameron, D. F.; Irwin, J. A. G.; Edye, L. A. Quantitatively expressed resistance to anthracnose (Colletotrichum gloeosporioides) in Stylosanthes scabra. Plant Pathology, London, v.37, n.4, p. 529-537, 1988.

7. Chakraborty, S.; Fernandes, C.D.; Charchar, M.J.D.A.; Thomas, M. Pathoł genic variation in Colletotrichum gloeosporioides infecting Stylosanthes spp. in a center of diversity in Brazil. Phytopathology, Saint Paul, v.92, p.553-562, 2002.

8. Chakraborty, S.; Pettitt, A.N.; Boland, R.M.; Cameron, D.F. Field evaluation of quantitative resistance to anthracnose in Stylosanthes scabra. Phytopathology, Palo Alto, v.80, n.3, p.1147-1154, 1990.

9. Chakraborty, S.; Perrott, R.; Charchar, M. J.D.A.; Fernandes, C.D.; Kelemu, S. Biodiversity, epidemiology and virulence of Colletotrichum gloeosporioides. II. Genetic and pathogenic diversity in Colletotrichum gloeosporioides isolates from eight species of Stylosanthes. Tropical Grasslands, Brisbane, v.31, n.5, p.387-393, 1997.

10. Charchar, M.J.D.A.; Anjos, J.R.N.; Gomes, A.C.; Tomaz, L.V.; Akimoto, A. K.; Kariia, C.T. Avaliação de acessos de Stylosanthes spp. em relação à antracnose, em condições de campo, no Distrito Federal, Brasil. Planaltina-DF: Embrapa Cerrados, 2002. p.14. (Boletim de pesquisa e desenvolvimento).

11. Cruz, C.D.; Carneiro, P.S.C. Modelos biométricos aplicados ao melhoramento genético. 2. ed. Viçosa: UFV, v.2,. 2006. 586 p.

12. Cruz, C.D. Programa Genes: Aplicativo computacional em genética e estatística, 2007. Disponível em: <http://www.ufv.br/dbg/genes/genes. htm.> Acesso em: 10 jul. 2013.

13. Davis, R.D.; Irwin, J.A.G.; Shepherd, R.K.; Cameron, D.F. Yeld losses caused by Colletotrichum gloeosporioides in three species of Stylosanthes. Australian Journal of Experimental Agriculture. v.27, p.67-72, 1987.

14. Fernandes, A.T.F.; Fernandes, C.D.; Grof, B. Reação de acessos de Stylosanthes capitata à antracnose. Pasturas Tropicales, Cali, v.15, n.1, p.23-26, 1993.

15. Fernandes, C.D.; Fernandes, A.T.F.; Chakraborty, S.; Ferreira, C.B.A. Vi- rulência de isolados de Colletotrichum gloeosporioides-agente etiológico da antracnose em Stylosanthes spp. Fitopatologia Brasileira, Brasília, v.23, p.241, 1998.

16. Fernandes, C.D. Resistência de progênies de Stylosanthes capitata e $S$. macrocephala à antracnose causada por Colletotrichum gloeosporioides. 2003. 90p. Tese (Doutorado em Proteção de Plantas) - Faculdade de Ciências Agronômicas, Universidade Estadual Paulista "Júlio de Mesquita Filho", Botucatu, 2003.

17. Grof, B.; Schultze-kraft, R.; Miller, F. Stylosanthes capitata Vog., some agronomic attributes, and resistance to anthracnose Colletotrichum gloeosporioides Penz. Tropical Grasslands, Cali, v.13: p.28-37, 1979.

18. Grof, B.; Fernandes, C. D.; Verzignassi, J. R. Recent advances in Sty losanthes research in Tropical America. In: International Grassland Congress, 20., Ireland United Kingdon. Anais. Wageningen: Wageningen Academic Publishers. 2005. p.339.

19. Iamsupasit, N.; Cameron, D.F.; Cooper, M.; Chakraborty, S.; Edye, L. Inheritance of anthracnose resistance in the tropical pasture legume Stylosanthes hamata. Australian Journal of Agricultural Research, Victoria, v. 46, n. 3, p. 1353-1364, 1995.

20. IBGE. Censo Agropecuário. 2010. Disponível em: </http://www.ibge. gov.br/home/estatistica/economia/agropecuaria/censoagro/2010/defaulttab_censoagro.shtm>. Acesso em: 12 jul. 2013.

21. IBGE. Rebanho de bovinos chega a 212,8 milhões de cabeças, 2012. Disponível em: <http:/www.agricultura.gov.br/animal/noticias/2012/10/ rebanho-de-bovinos-chega-a-212-milhoes-de-cabecas $>$. Acesso em: 10 dez. 2013.

22. IMEA. Dados da pecuária do estado do Mato Grosso, 2009 Disponível em: $<$ http://www.imea.com.br/upload/pdf/arquivos/Apresentacao_Rebanho_bovino.pdf $>$ Acesso em: 14 jul. 2013.

23. Kelemu, S.; Badel, J.L.,; Moreno, C.X.; Miles, J.W. Virulence spectrum of South American isolates of Colletotrichum gloeosporioides on selected Stylosanthes guianensis genotypes. Plant desease, Cali, v.80, p.13551358, 1996.

24. Kelemu, S.; Badel, J.L.; Moreno, C.X.; Rodriguez, M.X.; Fernandes, C.D.; Charchar, M.J.D’A. Biodiversity, epidemiology and virulence of Colletotrichum gloeosporioides- I. Genetic and pathogenic diversity in isolates from S. guianensis. Tropical Grasslands, Brisbane, v.31, n.5, p.387-392, 1997.

25. Lenné, J. M. Diseases of Stylosanthes. In: Lenné, J. M.; Trutmann, P. Diseases of Tropical Pasture Plants. Wallingford, CAB/CIAT/NRI. p.21-42, 1994

26. Lenné, J. M.; Turner, J. W.; Cameron, D. F. Resistance to diseases and pests of tropical pasture plants. Tropical Grassland, v.14, p.146-152, 1980.

27. Marchi, C.E.; Fernandes, C.D.; Guimarães, L.R.A.; Fabris, R.L.; Borges, M.F.; Trentin, R.A.; Jerba, V.F. Atividade pectinolítica de Colletotrichum gloeosporioides e a relação com a agressividade ao Stylosanthes spp. Bragantina, Campinas, v.68, n.2 , p.423-433, 2009.

28. Marchioro, V.S.; Carvalho, F.I.F.; Oliveira, A.C.; Lorencetti, S.; Binin, G.; Silva, J.A. G.; Kurek, A.J.; Hartwig, I. Herdabilidade e correlações para caracteres de panículas em populações segregantes de aveia. Revista Brasileira de Agrociencia, Brasília, v.9, n.4, p.323-328, out./dez. 2003.

29. Matiello, R.R.; Barbieri, R.L.; Carvalho, F.I.F. Resistência de plantas a moléstias fúngicas. Ciência Rural, Santa Maria, v.27, n.1, p.161-168, 1997

30. Menezes, M. Aspectos biológicos e taxonômicos de espécies do gênero taxo nômico. Anais da Academia Pernambucana de Ciências Agronômicas, Recife, v.3, p.170-179, 2006.

31. Miles, J.W.; Lascano, C.E. Status of Stylosanthes development in other countries. I. Stylosanthes development and utilization in South American. Tropical Grasslands, Cali, v.31, p.454-459, 1997.

32. Miranda, C.H.B.; Fernandes, C.D.; Cadisch, G. Quantifying of nitrogen fixed by Stylosanthes. Pasturas Tropicales, Cali, v.21, n.1, p.64-69, 1999.

33. Mohlembrock, R. H. A revision of the genus Stylosanthes. Annals of the Missouri Botanical Garden. v.44, p.299-355, 1957.

34. Pascholati, S. F; Leite, B. Hospedeiro: mecanismos de resistência. In: Bergae min Filho, A.; KImati, H.; Amorim, L. Manual de Fitopatologia: princípios e conceitos. 3. ed. São Paulo: Agronômica Ceres, 1995. p.417-453.

35. SAS - STATISTICAL ANALYSES SYSTEM. SAS/STAT 2002: user's guide: statistics version 8e, CD-ROM. Cary, 2002.

36. Segovia, R.T Seis ciclos de seleção entre e dentro de familiar de meios irmãos no milho (ZeamaysL.) Centralmex. 1976. 98p. Tese (Doutorado em Agronomia) Escola Superior de Agricultura Luiz de Queiroz, Universidade de São Paulo, Piracicaba, 1976.

37. Shaner, G. \& Finney, R.E. The effects of nitrogen fertilization on the expresp 
sion of slow-mildwing in knox wheat. Phytopathology, Saint Paul, v.67, p.1051-1055, 1977.

38. Thomas, D.; Lascano, C.E.; Vera, R.R. A tropical pasture legume for poor soils. Span, v.30, n.2, p.59-61, 1987.

39. Vale, F.X.R.; Jesus Júnior, W.C.; Liberto, J.R.; Souza, C.A. Quantificaf ção de doença e do crescimento do hospedeiro. In: Vale, F. X. R.; Jesus Junior, W. C.; Zambolim, L. Epidemiologia aplicada ao manejo de doenças de planta. Belo Horizonte: Perfil, p.89-124, 2004.

40. Van Der Plank, J.E. Principles of plant infection. New York: Academic Press, 1975. 210p.

41. Weeds, P.; Chakraborty, S.; Fernandes, C.D.; Charchar, M.J.D.A.; Ra; mesh, C.R.; Kexian, Y.; Kelemu, S. Genetic diversity in Colletotrichum gloeosporioides from Stylosanthes at centres of origin and utilization. Phytopathology, Saint. Pau,1 v.93, n.1, p.176-185, 2003. 